\title{
Filantropía, asistencia y epidemias en Brasil
}

\section{Gisele Sanglard (*), Luiz Otávio Ferreira $(*)$, Maria Martha de Luna Freire $(* *)$, Maria Renilda Nery Barreto $\left(^{* *}\right)$ y Tânia Salgado Pimenta (*)}

$\left(^{*}\right)$ Casa de Oswaldo Cruz/Fiocruz

$\left({ }^{* *}\right) \quad$ Universidade Federal Fluminense (UFF).

$\left({ }^{* *}\right)$ Centro Federal de Educação Tecnológica Celso Suckow da Fonseca.

Dynamis

[0211-9536] 2011; 31 (1): 13-20

Los acalorados debates promovidos por la propuesta del presidente Barak Obama sobre la reforma del sistema de salud en Estados Unidos buscando la ampliación del alcance de los servicios de salud para llegar hasta el 97\% de los norte-americanos en el año 2019 apuntan a una intensificación de la reflexión sobre el papel del Estado en las políticas de protección social. Ante la vertiginosa elevación de los costes de la atención en salud y la progresiva exclusión de grupos poblacionales cada vez más amplios, la respuesta de una mayor intervención gubernamental y el aporte de recursos para implementar la reforma fue, en general, bienvenida ${ }^{1}$.

Al contrario de los Estados Unidos de América, en Brasil existe un consenso aparente alrededor del carácter público y universal de la atención en salud ${ }^{2}$ y, en particular, sobre el papel del Estado en la oferta de estos servicios. La historiografía brasileña se ha acostumbrado a asociar la efectiva institucionalización de la asistencia pública en salud al régimen de cuño anti-liberal vigente entre 1930 y 1945 conocido como la era Vargas. Este régimen fue responsable del establecimiento de un conjunto de reformas políticas, sociales y administrativas que convirtieron al Estado brasileño

\footnotetext{
1. La profesora Lígia Bahia, del Núcleo de Estudos de Saúde Coletiva de la Universidade Federal do Rio de Janeiro (UFRJ), critica, sobretodo, su carácter privatista y mercadológico. Para ella, se trató, más que de una universalización del acceso al cuidado, de una extensión de la oferta de seguro privado a los segmentos sin asistencia. Ver http://www.cebes.org.br/verBlog.asp

2. A través del Sistema Único de Salud (SUS) que integra el sistema de derechos sociales instituido por la Constitución brasileña de 1988.
} 
contemporáneo en el principal protagonista del proceso de modernización económica y social. Durante una época de radicalización política y bajo la influencia de un activo movimiento sanitarista, se pusieron en marcha las primeras políticas públicas a cargo del entonces recién creado Ministerio de Educación y Salud Pública ${ }^{3}$.

Sin embargo, la promulgación de políticas de salud pública durante este periodo no significó un cambio inmediato de los valores y prácticas culturales asociadas a la asistencia sanitaria y social. En la tradición brasileña, la prestación de auxilio a las personas enfermas y desvalidas era una atribución de la sociedad. Motivadas por el compromiso cristiano de la caridad y por la búsqueda de prestigio y poder, las elites locales asumieron la tarea de organizar los servicios de asistencia. En esa misión destacó la acción de la Hermandad de la Misericordia que por intermedio de su red de hospitales y asilos, popularmente conocidos como Santas Casas de la Misericordia, fue la responsable de prestar asistencia a los pobres, a los esclavos y a otros grupos sociales específicos como soldados, marineros e inmigrantes ${ }^{4}$.

Aunque las Misericordias no eran instituciones públicas, es incorrecto pensar que la actuación de la hermandad en la prestación de asistencia fue indiferente a la acción del Estado imperial brasileño. A lo largo del siglo XIX, periodo en el cual Brasil transitó de la situación de colonia portuguesa a la condición de monarquía constitucional independiente, la caridad -individual y colectiva - era la única manera socialmente reconocida de prestación de asistencia. Lo que le atribuye singularidad a este modelo de asistencia es el

3. Fonseca, Cristina M. O. Saúde no Governo Vargas (1930-45). Dualidade institucional de um bem público. Rio de Janeiro: Editora Fiocruz; 2007. Hochman, Gilberto. A Era do saneamento - as bases da política de saúde pública no Brasil. São Paulo: Hucitec/ANPOCS; 1998.

4. Russel-Wood, A. J. R. Fidalgos e filantropos: a Santa Casa da Misericórdia da Bahia, 1550 - 1755. Brasilia: Editora da Universidade de Brasília; 1981. Abreu, Laurinda. Igreja, caridade e assistência na Península Ibérica (sécs. XVI-XVIII). Évora: Edições Colibri; 2003. Araújo, Maria Marta L. de, org. As Misericórdias das duas margens do Atlântico: Portugal/Brasil (séculos XV-XX). Cuiabá: Carlini e Caniato; 2009. Boschi, Caio César. Os leigos e o poder. São Paulo: Ed. Ática; 1986. Caponi, Sandra. Da compaixão à solidariedade: uma genealogia da assistência médica. Rio de Janeiro: Editora Fiocruz; 2000. Lopes, Maria Antônia. Pobreza, assistência e controle social em Coimbra (1750-1850). Coimbra: Palimage editores; 2000. Mesgravis, Laima. A Santa Casa de Misericórdia de São Paulo (1599?-1884). São Paulo: Conselho Estadual de Cultura; 1976. Sá, Isabel dos Guimarães. Quando o rico se faz pobre: misericórdias, caridade e poder no império português, 1500-1800. Lisboa: Comissão Nacional para as comemorações dos descobrimentos portugueses; 1997. 
tejido de relaciones sociales que involucraban en la misma trama lo público y lo privado, lo laico y lo religioso, la piedad y la racionalidad.

Aunque no podamos hablar de declive de la caridad como forma socialmente reconocida de prestación de asistencia al comienzo del régimen republicano brasileño (década de 1890), ya es posible percibir la presencia de otros modelos asistenciales en forma de instituciones filantrópicas dedicadas a la prestación de asistencia en salud, sobre todo en el ámbito de la salud materno-infantil ${ }^{5}$ y también de entidades civiles beneméritas o de asociaciones de mutuas que ofrecían protección y asistencia a determinados grupos sociales ${ }^{6}$. No hay consenso historiográfico sobre el significado social y político de esos nuevos modelos, consolidados durante la llamada Primera República brasileña (1889-1930), pero es bastante probable que las instituciones filantrópicas y la asistencia destinada a grupos sociales específicos (especialmente trabajadores) inspiraran la formulación de políticas de atención en salud adoptadas en el segundo periodo republicano brasileño, inaugurado en 1930 .

Recientemente, las relaciones entre Estado y sociedad se han visto afectadas por nuevos desafíos impuestos por enfermedades emergentes agravadas por el aumento de la circulación de personas, bacterias y virus, como es el caso de la pandemia de SIDA. Estas nuevas enfermedades actualizan antiguas luchas entre derechos individuales y responsabilidad colectiva y se benefician del análisis de experiencias del pasado para iluminar el presente y el futuro.

En la década de 1990, historiadores que se centraron en el estudio de las actividades y las concepciones de los grupos subalternos encontraron en estos contextos epidémicos momentos singulares para profundizar nuestro entendimiento del papel del Estado frente a esas situaciones y de las relaciones entre los diferentes grupos sociales ${ }^{7}$. Esos estudios dejaron al descubierto el hecho de que a partir de los grandes brotes de fiebre amarilla,

5. Marcílio, Maria Luiza. História social da criança abandonada. São Paulo: HUCITEC; 2006. Venâncio, Renato Pinto. Famílias abandonadas: assistência à criança de camadas populares no Rio de Janeiro e em Salvador - séculos XVIII e XIX. São Paulo: Papirus; 1999.

6. Viscardi, Claudia. Experiências da prática associativa no Brasil (1860-1880). TOPOI - Revista de História. 2008; 9 (16): 117-136.

7. David, Onildo R. O inimigo invisível: epidemia na Bahia no século XIX. Salvador: EdUFBA/Sarah Letras; 1996. Chalhoub, Sidney. Cidade febril: cortiços e epidemias na Corte Imperial. São Paulo: Companhia das Letras; 1996. Beltrão, Jane F. Cólera, o flagelo da Belém do Grão-Pará. Belém: MPEG/UFPA; 2004. 
cólera y peste, ocurridos en las principales ciudades de la costa brasileña en la década de 1850, las epidemias se convirtieron en un grave problema social que exigió cada vez más la movilización del Estado y de la medicina local para promover acciones sanitarias de prevención y asistencia a las poblaciones afectadas ${ }^{8}$. Abordajes y énfasis diferentes pueden observarse en estas investigaciones que se han detenido en aspectos relacionados con el pensamiento médico, las instituciones y las políticas de salud y las relaciones entre los diferentes grupos de terapeutas y el modo en que la sociedad se enfrentó a estas calamidades 9 .

El esfuerzo historiográfico reciente para analizar de forma más detallada las relaciones entre Estado, asistencia y filantropía en diferentes contextos culturales brasileños, expresado en el aumento del número de tesis y disertaciones que versan sobre asistencia, filantropía, salud pública, epidemias y políticas públicas en salud, nos animó a organizar el Seminario Internacional «Estado, filantropía y asistencia» en Río de Janeiro en noviembre de $2009^{10}$. Las jornadas tuvieron por objetivo poner en común estudios recientes dirigidos a analizar los significados históricos y socio culturales de las prácticas asistenciales en las sociedades modernas, en particular en las sociedades ibero-americanas.

Así, contando con invitados de diversas regiones de Brasil, de Portugal y de España fue posible discutir la relación históricamente construida entre Estado, asistencia y filantropía en el ámbito de la salud. Pues si hoy consideramos innegable que la forma en la que una sociedad percibe, evalúa y se organiza para resolver sus problemas de salud está históricamente justificada, resulta obvio que el conocimiento de experiencias de épocas pasadas es fundamental para afrontar los asuntos de actualidad.

8. Hasta por lo menos la pandemia de gripe de 1918, Brasil fue un país constantemente asolado por epidemias.

9. Benchimol, Jaime. Dos micróbios aos mosquitos. Febre amarela e a revolução pasteuriana no Brasil. Rio de Janeiro: Editora Fiocruz/Editora da UFRJ; 1999. Bertucci, Liane M. Influenza, a medicina enferma. Ciência e práticas de cura na época da gripe espanhola. Campinas: Editora UNICAMP; 2004. Bertolli Filho, Claudio. A gripe espanhola em São Paulo: epidemia e sociedade. Rio de Janeiro/São Paulo: Paz e Terra; 2003. Souza, Christiane M. Cruz de. A gripe espanhola na Bahia: saúde, política e medicina em tempos de epidemia. Salvador/Rio de Janeiro: EDUFBA/FIOCRUZ; 2009.

10. Con el apoyo de la Fundação Carlos Chagas Filho de Amparo à Pesquisa do Estado do Rio de Janeiro (FAPERJ) y de la Coordenação de Aperfeiçoamento de Pessoal de Nível Superior (CAPES). 
El dossier «Filantropía, asistencia y epidemias en Brasil» reúne algunos de los trabajos presentados en las mesas-redondas «Asistencia, cultura y sociedad»y «Asistencia en tiempos de epidemias» que formaron parte de esas jornadas. Se trata de estudios que abarcan diversas regiones de Brasil - Bahia, Minas Gerais, Río de Janeiro y Sao Paulo- en diferentes épocas, propiciando un mejor entendimiento acerca del modo en que se configuró la atención sanitaria en el país.

En su artículo, Tânia Salgado Pimenta estudia la organización de la atención en Río de Janeiro a mediados del siglo XIX. Analizando el periodo de eclosión de las epidemias de fiebre amarilla (1849-50) y de cólera (185556) en la capital del Imperio brasileño, la autora identifica una inflexión en la forma cómo el Estado se posicionaba en relación a la salud pública, y señala una reestructuración de las iniciativas públicas y privadas. Utilizando como fuentes las correspondencias entre el gobierno Imperial y la administración de la Santa Casa de la Misericordia, los oficios de la Junta de Higiene Pública y los periódicos de la época, muestra la creciente demanda de servicios del hospital de la Misericordia a lo largo del siglo XIX, una situación que repercutió en la redefinición de la categoría de pobre y en el perfil de las personas que podrían ser atendidas gratuitamente en sus dependencias. A pesar del aumento de la oferta de camas y del número de médicos y funcionarios del hospital, el mayor problema de la atención pública centrado en el Hospital de la Misericordia era estructural, pues dicho aumento no acompañaba al elevado crecimiento de la población de Río de Janeiro. Por otro lado, aunque el Estado no asumiera directamente la atención a la salud de la población, se observa una creciente intervención y auxilio financiero al hospital y enfermerías de la Santa Casa.

El artículo «Epidemias, estado y sociedad: Minas Gerais en la segunda mitad del siglo XIX» aborda dos episodios epidémicos, de cólera (1855-1856) y de viruela (1873-1875), señalando las especificidades de la provincia de Minas Gerais. Durante el siglo XVIII, debido a la producción minera, la región había sobresalido económica y socialmente. A lo largo del siglo XIX, sin embargo, posteriormente a la crisis minera, la provincia del interior de Brasil pasó por un proceso de ruralización y el artículo de Anny Jackeline Torres Silveira se centra, justamente, en pequeños pueblos y ciudades, un contexto bien diferente de los estudios que privilegian los grandes centros urbanos de la época. En su investigación, la autora analiza la organización de servicios de asistencia para el abordaje de esas epidemias, privilegiando, de un lado, la movilización de la sociedad y del otro, la actuación del 
poder público, identificando las permanencias, rupturas y contradicciones involucradas en el proceso. Su estudio se completa con el análisis de Rita de Cássia Marques sobre la asistencia hospitalaria en Minas Gerais. Anny Silveira señala el impacto de las epidemias sobre los servicios en salud disponibles en la provincia, cuando buena parte de la población permaneció sin asistencia. Resalta, además, que la propia sociedad se movilizó para socorrer a los afectados por las epidemias, un hecho que no era novedad ya que la asistencia a la salud era concebida en el periodo como un asunto a cargo de la caridad y la filantropía.

El texto de Dilene Raimundo do Nascimento analiza la epidemia de peste bubónica ocurrida en el puerto de Santos (Sao Paulo) en 1899. La autora presenta las seguridades e inseguridades de los conocimientos y terapéuticas científicas sobre la enfermedad en un momento de afirmación de la medicina pasteuriana. La irrupción de la epidemia en el puerto paulista de Santos, debido a su impacto sobre el flujo inmigratorio de trabajadores europeos para las haciendas de café del interior del estado de Sao Paulo, alarmó al gobierno y movilizó a los médicos higienistas, en especial Oswaldo Cruz y Vital Brasil. Entre otras consecuencias, la epidemia funcionó como gatillo para la organización de un aparato sanitario en el país, constituido por hospitales de aislamiento, laboratorios bacteriológicos e instalaciones para producción de sueros y vacunas. Para la autora, la epidemia de peste bubónica representó una oportunidad para establecer, de forma pionera, acciones conjuntas y organizadas entre diferentes estados brasileños para enfrentar los problemas sanitarios.

El principal objetivo del artículo de Christiane Souza es identificar y problematizar las motivaciones que llevaron a las elites del estado de Bahía a transformar la atención en salud en un proyecto político. La autora señala cómo, a través de las acciones emprendidas por el Estado, la preocupación por la salud se trasladó del ámbito de la esfera privada al espacio público. El escenario es la ciudad de Salvador — una de las ciudades más antiguas e importantes de Brasil, fundada en 1549- en el cambio del siglo XIX al XX. De forma idéntica a lo ocurrido en otros centros urbanos de la costa brasileña, Salvador sufría las epidemias como un problema social crónico. La autora describe cómo, en medio de disputas políticas entre las elites locales, las epidemias de fiebre amarilla, viruela, peste, malaria, gripe y cólera impusieron la necesidad de un proyecto de modernización urbana y de higienización de la ciudad, lo que incluía la aculturación sanitaria de la población en su mayoría constituida por ex-esclavos y sus descendientes. 
Siguiendo el modelo de las reformas sanitarias en curso en las ciudades de Río de Janeiro y Sao Paulo, el proyecto de las elites del estado de Bahía también se preocupaba por la organización de un dispositivo sanitario moderno que incorporaba la creación de un laboratorio bacteriológico, antirrábico y vacunogénico y espacios hospitalarios.

La historiografía muestra que la práctica de la asistencia caritativa en instituciones hospitalarias perduró durante siglos, incluso habiéndose transformado los hospitales, cada vez más, en espacios de terapéutica en detrimento de la caridad ${ }^{11}$. La propia idea de atención englobaba, aún en los inicios del siglo XX, un vasto y amplio abanico de acciones a las cuales se les atribuía un carácter público - desde los cuidados dirigidos a la infancia y maternidad, hasta la vejez y la locura. Incluía, así, un conjunto diversificado de instituciones como hospitales, asilos, orfanatos, colonias, salas cunas, ligas, puestos médicos, maternidades, hospicios, dispensarios, policlínicas, cuyos límites de actuación eran tenues y permeables. De ese modo, además del Estado, la asistencia pública era ejercida por diversas entidades de caridad y/o filantrópicas como las sociedades civiles y religiosas, fundaciones asistenciales y otros grupos comunitarios.

El artículo de Rita de Cássia Marques «La caridad fundando hospitales en Minas Gerais (Brasil), siglos XVIII-XX» retrocede al siglo XVIII para analizar cómo las iniciativas caritativas practicadas por católicos, legos o religiosos subsidiaron la construcción de hospitales en Minas Gerais. Señala que fue un proceso que se dio, sobre todo, alrededor de la organización de hermandades. El caso de Minas Gerais es semejante al de otros estados brasileños en el periodo, donde las Santas Casas eran las principales, si no las únicas, instituciones asistenciales. El texto explora, además, las singularidades del estado de Minas Gerais y centra su investigación en tres tipos de instituciones: las Hermandades de la Santa Casa de Misericordia y de San Vicente de Paula y las asociaciones de médicos católicos, y en los respectivos hospitales fundados por ellos. Resalta, finalmente, que aunque

11. Souza, Marco Antônio. A economia da caridade: estratégias assistenciais e filantrópicas em Belo Horizonte. Belo Horizonte: Editora Newton Paiva; 2004. Gandelman, Luciana M. Entre a cura das almas e o remédio das vidas: o recolhimento de órfãs da Santa Casa de Misericórdia do Rio de Janeiro e a caridade para com as mulheres (ca. 1739-1830). Rio de Janeiro: Secretaria Municipal das Culturas; 2008. Marques, Rita de C. A imagem social do médico de senhoras no século XX. Belo Horizonte: COOPMED; 2005. Mota, André; Schraiber, Lilia B., orgs. Infância \& saúde: perspectivas históricas. São Paulo: Ed. HUCITEC/FAPESP; 2009. Castro Santos, Luiz Antonio; Faria, Lina. Saúde \& História. São Paulo: Ed. HUCITEC; 2010. 
el ideal de caridad cristiana había inspirado acciones asistenciales hasta el siglo XX, en los años 1940 y 1950 surgieron instituciones hospitalarias fundadas por médicos de otras creencias religiosas, como el Hospital Evangélico (1957) y el Hospital Espírita André Luiz (1949). Además de discutir las relaciones entre sociedad, Estado y asistencia en Brasil más allá del eje Río de Janeiro - Sao Paulo - ciudades habitualmente privilegiadas por la historiografía nacional-, el artículo de Rita de Cássia incorpora nuevos personajes y asuntos al debate, confiriéndole mayor amplitud y complejidad y sugiriendo nuevas posibilidades de investigación. 